\title{
Identification of Novel Susceptibility Genes for Breast Cancer - Genome-Wide Association Studies or Evaluation of Candidate Genes?
}

\author{
Alfons Meindl \\ Abt. Tumorgenetik, Frauenklinik, Klinikum rechts der Isar an der Technischen Universität München, Germany
}

\section{Key Words}

Breast cancer - Genome-wide association studies .

Polygenic inheritance · Genetic counselling

\section{Summary}

To determine the genetic components that constitute polygenic traits in familial or sporadic breast cancer, lowrisk variants on the one hand and mutations conferring moderate penetrance on the other hand have to be identified. While members of the latter group were found by comprehensive screening of candidate genes which are, like the 2 highly penetrant genes BRCA1/BRCA2, located in the DNA repair pathway, the development of novel techniques was urgently needed to identify low-risk variants. The hybridization of chips which contain several hundred thousand single nucleotide polymorphisms (SNPs) with several thousand DNAs from either sporadic breast cancer cases or healthy controls (genome-wide association study, GWAS) has already led to the detection of at least 8 low-risk variants, conferring odds ratios of 1.06-1.64. As they are common in the population, it is likely that extended GWAS will develop a genetic pattern that is able to discriminate women suitable or not for population screening programs.

\section{Introduction}

Although a prominent fraction (30-40\%) of clear (3 or more cases of breast cancer, including 2 diagnosed before the age of 50) familial breast cancer cases can be explained by mutations

\author{
Schlüsselwörter \\ Brustkrebs · Genomweite Assoziationsstudien . \\ Polygene Vererbung · Genetische Beratung
}

\section{Zusammenfassung}

Um die genetischen Komponenten zu bestimmen, welche die polygenen Eigenschaften von familiärem oder sporadischem Brustkrebs ausmachen, müssen einerseits Niedrigrisiko-Genvarianten und andererseits moderat wirkende Mutationen identifiziert werden. Während Mitglieder der letzteren Gruppe durch umfangreiches Screening von infrage kommenden Genen, welche wie die 2 hochpenetranten Gene BRCA1/BRCA2 im DNA-Reparatur-Signalweg lokalisiert sind, identifiziert werden konnten, war für die Bestimmung von Niedrigrisiko-Varianten die Entwicklung neuer Techniken dringend nötig. Die Hybridisierung von Chips, welche mehrere hunderttausend SNPs (single nucleotide polymorphisms) mit mehreren tausend DNAs von sowohl Patienten mit sporadischem Brustkrebs als auch Nichterkrankten enthalten (genomweite Assoziationsstudien, GWAS), hat bereits zur Entdeckung von mindestens 8 Niedrigrisiko-Varianten geführt (Odds Ratio: 1.06-1.64). Auf Grund ihres häufigen Vorkommens in der Bevölkerung ist es wahrscheinlich, dass erweiterte GWAS zur Entwicklung eines genetischen Musters führen werden, mit welchem für Screening-Programme geeignete Frauen von ungeeigneten unterschieden werden können.

\begin{tabular}{ll}
\hline KARGER & ๑ 2009 S. Karger GmbH, Freiburg \\
Fax +497614520714 & Accessible online at: \\
Information@Karger.de & www.karger.com/brc \\
www.karger.com &
\end{tabular}


Indeed, the most common form of breast cancer is now considered a multifactorial disease caused primarily by the combined effects of several genetic variants [1] and may only be modulated by environmental factors occurring in the post-industrial Western world. As the latter factors are beyond the scope of this article, I will focus on the risk-contributing genetic factors.

Two groups of novel susceptibility factors can be clearly distinguished: Firstly, conventional but rare mutations in genes involved in DNA repair mechanisms, which affect protein function and result in moderate penetrance, and secondly, single nucleotide polymorphisms (SNPs) which are located in genes that have not necessarily been associated with tumorigenesis before. The latter do not usually result in an altered protein but rather change the amount of protein produced within the cell. Low-risk variant further means that such SNPs are not only present in the patients to be investigated but also, in higher or lower numbers, in healthy controls. The larger the impact (conferring a risk) of such a variant (odds ratio, OR), the lower is the number of case and control samples required for statistically relevant observations. For example, the 2 most prominent low-risk variants in the FGFR2 (fibroblast growth receptor 2) and TOX3 (TOX high mobility group box family member 3) genes were originally identified by the compared analysis of 30,000 cases and controls each [1] but could later be confirmed in much smaller samples (about 1,500) of sporadic [3] or hereditary cases [Hemminki K, et al., personal communication]. This is due to their relatively strong impact. One aim of further studies now is to determine a pattern of polymorphisms which can reliably discriminate between women at risk and not at risk. As it still requires prospective validation, this pattern has to be determined in special Counselling and Diagnostic Centres located at universities. A second aim is to improve risk assessment for first-degree relatives of familial cases who have tested negative for BRCA1/BRCA2 mutations.

\section{Identification of Low-Risk Variants by Genome-Wide Association Studies (GWAS)}

During the last 2 years, a huge amount of new data has been generated by the application of genome-wide association studies (GWAS) [1-3]. New tools like high-density SNP arrays provided by different companies (e.g. Affymetrix Inc., Santa Clara, CA, USA or Illumina Inc. San Diego, CA, USA), are now available for these studies to identify genetic variants associated with an increased breast cancer risk in large groups containing thousands of patients and controls. This means, in an association study, the frequency of an SNP to be validated is compared between breast cancer cases and controls. Statistically significant differences in allele frequencies are more easily demonstrated for variants exhibiting a population frequency $>5 \%$, and false positives can be avoided by the inclusion of tens of thousands of sporadic samples $(>20,000)$ or several thousand genetically enriched cases $(2,000-4,000)$.
The aim of these studies has been to identify a sufficient number of polymorphisms, each expected to contribute only to a minor extent to the individual risk. Since most of these variants occur with a high frequency in the investigated populations and therefore also in the investigated cases (table 1), they might have a significant impact on breast cancer risk [4]. For a critical discussion of the epidemiological credibility of these studies, which depends on the number of studies and patients included, replication and protection from bias, and regarding different genome-wide approaches for the identification of susceptibility genes, please refer to the most recently published review by Seng and Seng [5].

There is currently a growing list of reports on common SNPs in genes or at specific chromosomal loci that have been identified in such GWAS performed mainly in sporadic cases: FGFR2 [1], TOX3 [1, 6], LSP1 [1], MAP3K1 [1], as well as a locus on $2 q 35$ [6] and $8 \mathrm{q}$ [1]. The ORs for heterozygous and for homozygous carriers are 1.1-1.3 and 1.2-1.6, respectively (table 1). Interestingly, a recent report of a three-phase GWAS in Ashkenazi Jews [7] confirmed the formerly reported [1, 3] association of breast cancer risk with the chromosomal region of FGFR2 on 10q and observed a new breast cancer risk locus in 6q22.33 (OR 1.41) comparing BRCA1/BRCA2-negative high-risk breast cancer cases with unaffected controls.

The strongest evidence for association with breast cancer has been demonstrated for SNPs located in the intron 2 of the FGFR2 gene which was mapped to the chromosome region 10q26. Fortunately, the risk prevalence of this variant allows the detection in genome-wide scans, since there is a sufficient difference in the according allele between cases and controls. Although the impact of the low-risk variant is modest, homozygous individuals at the age of 70 have a $10.5 \%$ risk for breast cancer compared with $5.5 \%$ in individuals who do not carry the trait. Finally, while the functional or biological consequences of most SNPs are as yet unclear, Meyer et al. [8] recently reported an altered binding affinity for transcription factors OCT1, RUNX2, and $\mathrm{C} / \mathrm{EBP}$ as a result of identified breast cancer susceptibility SNPs in intron 2 of FGFR2 that lead to increased FGFR2 expression. Interestingly, FGFR2 plays a role within the oestrogen pathway, strengthening the hypothesis that hormonal imbalances influence the initiation of breast cancer.

Another low-risk variant which has been confirmed in different populations with high statistical significance, is located at $16 \mathrm{q} 12$, in the $5^{\prime}$ region of the gene TOX3. Although the role of its encoded protein is still a matter of debate (due to the favoured hypothesis that it codes for a transcription factor), it seems to not play a role in the oestrogen pathway.

A third low-risk variant, which might link female breast cancer to the immune system, is located within the gene LSP1 which encodes for lymphocyte specific protein 1 . Together with FGFR2 and TOX3, it might play an even more pronounced role in high-risk familial cases (see below).

All other low-risk variants published so far have to be validated in multiple other populations as they might be popu- 
Table 1. Breast cancer suspectibility genes with low or moderate penetrance

\begin{tabular}{|c|c|c|c|c|c|c|}
\hline \multirow[t]{2}{*}{ Gene/locus } & \multirow[t]{2}{*}{ Name } & \multirow{2}{*}{$\begin{array}{l}\text { Mutation/ } \\
\text { reference SNP }\end{array}$} & \multirow[t]{2}{*}{ Location } & \multirow[t]{2}{*}{ Function } & \multicolumn{2}{|c|}{ Odds ratio } \\
\hline & & & & & het & hom \\
\hline \multicolumn{7}{|c|}{ Common low penetrance breast cancer susceptibility SNPs } \\
\hline FGFR2 & fibroblast growth factor receptor type 2 & $\begin{array}{l}\text { rs2981582 } \\
\text { rs1219648 }\end{array}$ & $10 \mathrm{q} 25.3-\mathrm{q} 26$ & $\begin{array}{l}\text { receptor for acidic and basic } \\
\text { fibroblast growth factors }\end{array}$ & 1.2 & 1.6 \\
\hline LSP1 & lymphocyte-specific protein 1 & rs3817198 & $11 \mathrm{p} 15.5$ & intracellular F-actin binding protein & 1.1 & 1.2 \\
\hline MAP3K1 & $\begin{array}{l}\text { mitogen-activated protein kinase kinase } \\
\text { kinase } 1\end{array}$ & rs889312 & $5 q 11.2$ & $\begin{array}{l}\text { integration of cellular responses } \\
\text { to mitogenic and metabolic stimuli }\end{array}$ & 1.1 & 1.3 \\
\hline TGFB1 & transforming growth factor, beta 1 & L10P & 19q13.1 & $\begin{array}{l}\text { control of proliferation, } \\
\text { differentiation and other functions }\end{array}$ & 1.1 & 1.2 \\
\hline TOX3 & TOX high mobility group box family & rs3803662 & 16q12.1 & regulation of transcription, & 1.3 & 1.6 \\
\hline & member 3 & & & DNA-dependent & 1.2 & 1.4 \\
\hline $2 q 35$ & - & rs13387042 & $2 q 35$ & - & 1.1 & 1.4 \\
\hline $8 \mathrm{q}$ & - & rs13281615 & $8 \mathrm{q}$ & - & 1.1 & 1.2 \\
\hline \multicolumn{7}{|c|}{ Rare, moderate penetrance breast cancer susceptibility genes } \\
\hline ATM & ataxia telangiectasia mutated & mutations & $11 q 22-q 23$ & DNA repair & 2.4 & - \\
\hline BRIP1 & $\begin{array}{l}\text { BRCA1 interacting protein C-terminal } \\
\text { helicase } 1\end{array}$ & mutations & $17 q 22.2$ & DNA repair & 2.0 & - \\
\hline CHEK2 & checkpoint kinase 2 & 1100delC & 22q12.1 & DNA repair & 2.0 & - \\
\hline PALB2 & partner and localizer of BRCA2 & mutations & $16 \mathrm{p} 12.1$ & DNA repair & 2.3 & - \\
\hline
\end{tabular}

$\mathrm{SNP}=$ Single nucleotide polymorphism; het = heterozygous; hom = homozygous .

lation-specific. This cannot, for example, be excluded for the low-risk variants at 2q35 [6] and 6q22.33 [7]. Preliminary results for the German population indicate only very minor effects, especially in genetically enriched cases. Thus, 6q22.33 might be restricted in its impact to the Ashkenazi population [Meindl and the German Consortium for Hereditary Breast and Ovarian Cancer, unpublished data].

\section{Relevance of Low-Risk Variants in Familial Cases}

The validation of most of these novel low-risk variants in highrisk families led to the observation of 2 interesting features: firstly, some of these low-risk variants, especially FGFR2, can modify the disease course for BRCA2 mutation carriers, and secondly, they might have a higher impact in familial than in sporadic cases.

By analysing 10,358 either BRCA1 or BRCA2 mutation carriers for the presence or absence of one or more identified low-risk variants, it was determined that especially the lowrisk variant present in the FGFR2 gene modifies the risk for BRCA2 mutation carriers (hazard ratio $(\mathrm{HR})=1.32)$ [9]. The impact is most striking for this variant and this group of mutation carriers. However, minor effects could also be observed for variants in the gene MAP3K1 in BRCA2 mutation carriers $(\mathrm{HR}=1.12)$, and for a variant in the TOX3 gene $(\mathrm{HR}=1.13)$ with an effect in both BRCA1 and BRCA2 mutation carriers. These observations have an important impact on genetic counselling and management. For example, the absolute risk of breast cancer by age 70 among BRCA2 mutation carriers is predicted to be $43 \%$ for the homozygous wild-type allele and $63 \%$ for individuals homozygous for the low-risk allele (the difference can be made higher by including the TOX3 variant). If more such risk alleles are identified by application of GWAS, the number of carriers for whom the risk can be modified substantially will significantly increase [9].

It has been hypothesized that gene mutations conferring moderate penetrance (see below) have a higher impact in clear familial cases. Similar effects might be possible for low-risk variants in hereditary cases tested negative for mutations in BRCA1/BRCA2. Indeed, evaluation of the low-risk variants identified in the FGFR2 and TOX3 genes showed higher ORs in familial compared to sporadic cases from Great Britain [D. Easton, personal communication]. Similar results could be demonstrated for the German population [K. Hemminki et al., personal communication].

Currently, further genome-wide association studies (including combined analysis) are underway comparing BRCA1/ BRCA2-negative familial and sporadic breast cancer cases with control cohorts. They will certainly identify new susceptibility polymorphisms and will possibly be able to investigate additional or synergistic effects of defined susceptibility polymorphisms [2].

\section{Possible Clinical Impact of Low-Risk Variants}

Whereas clear criteria for genetic testing of BRCA1 and BRCA2 have been defined $[10,11]$ and several models for determining carrier probabilities and cancer risks of individuals with a fam- 
ily history of breast cancer are publicly available [12, 13], it is still controversial when and how the increasing list of these genetic susceptibility factors can be integrated into routine clinical care. So far, no clinical decisions can be based on their presence or absence, and genetic testing may currently only provoke great insecurity [4], both for counselees and medical doctors. As argued by Offit and Garber [14], routine investigation may actually lead to unnecessary interventions in carriers of susceptibility mutations, and non-carriers may feel a false sense of security [14]. In contrast, genetic counselling of BRCA1/BRCA2 mutation carriers regarding modifier polymorphisms like for FGFR2, MAP3K1, RAD51, and TOX3 may be possible as the additional analysis of certain polymorphisms might specify the breast cancer risk and allow further individualization of clinical management regarding the surveillance program, decision-making concerning risk-reducing surgery, and therapeutic strategies. Finally, and this is most likely the strongest argument, clinical programs to meet the needs of these high-risk patients have been set up in most countries [11, 15].

In addition to the identification of new polymorphisms and the validation of their relative risk in different large cohorts, it is essential to understand the combined effect of different polymorphisms and to establish reliable risk prediction models before stepping forward to routine investigations. Although the risks conferred by an individual locus are rather small, some risk alleles may act multiplicatively. Thus, breast cancer risk among women carrying 14 risk alleles is estimated to be 6 times as high as among women carrying none of these risk alleles [16]. In the future, screening programs may be adapted to the individual genetic risk, e.g. modifying age of initiation and investigation intervals of mammography, integration of magnetic resonance imaging and/or risk-reducing surgery. Hopefully, this will lead to intensified screening in high-risk individuals while sparing unnecessary and even potentially harmful screening in women with very low-risk profiles. However, the clinical utility of such an individualized genome-based approach has to be validated and principles for the implementation of genetic testing of new susceptibility mutations and/or polymorphisms have to be established from an individual as well as from a population and health care system point of view $[17,18]$. Further studies will probably soon identify polymorphisms associated with different response rates to certain therapies or histological subtypes, and particular SNPs may even serve as therapeutic targets $[6,19,20]$. Although none of the known variants could be associated with chemoprevention so far, a variant within $\mathrm{NAD}(\mathrm{P}) \mathrm{H}$ :quinone oxidoreductase 1 has been linked to epirubicin resistance [19] and a variant within the FGFR4 gene with endocrine therapy resistance [21], indicating that at least some of such low-risk variants will influence therapeutic decisions in the future.

In summary, based on the current knowledge, there is at present no validated experimental design or accepted genetic model that demands screening of the known common lowpenetrance genes and loci to specify individual breast cancer risk. On the other hand, a small or modest number of predisposing alleles might be able to distinguish women at high risk for breast cancer from women at low risk, especially in the context of population screening programs. For example, a 50 -year-old woman in the general population in Great Britain has a $2.3 \%$ risk of breast cancer within the next 10 years of her life [16]. Under the assumption that this is the threshold at which a screening program makes sense, it is reasonable to offer screening to all women with that level of risk, for example first degree relatives of early onset (diagnosed before the age of 36 years) or even of all premenopausal cases. Or vice versa, women at lower risk (for example 1\%) could be excluded from prevention programs. The implementation of such a strategy would increase the efficiency of screening programs, as it would specifically target women at risk. In addition, expensive screening tests (such as magnetic resonance imaging) should only be used in high-risk subgroups which can in part be defined by their genetic repertoire [16].

Likewise, in the long term, one cannot exclude that the proved interaction or co-segregation of such variants with mutations harbouring moderate penetrance (see below) make them attractive for a more focussed risk prediction. Moreover, in the near future, with the new generation of low-cost high-throughput sequencing technologies and powerful risk prediction models integrating family history, lifestyle factors, and the available genetic information, individual risk classification may allow adequate preventive management, intensified in those with higher risks but also reduced in those with lower risk levels. With these powerful, validated risk estimation tools in hand, it might be possible to reach a point where statistical significance meets clinical relevance, and screening programs based on genetic information will lead to reduced breast cancer-associated mortality.

\section{Can GWAS Completely Substitute the Evaluation of SNPs in Candidate Genes?}

Chip hybridization technology is theoretically not the only way to identify and validate novel low-risk variants for breast cancer. For example, evaluation of SNPs located in genes associated with tumorigenesis has been performed for several years. However, there have been 2 major restrictions: i) the number of variants that have been evaluated is rather small as compared with the total number of genes and variants present in the human genome; and ii) the number of cases and controls investigated has been too low. Consequently, most evaluations could not be replicated by the more powerful and reliable GWAS approach which relies on the analysis of several thousand cases and controls. Hence, the application of these experiments has now made it likely that most of the SNPs located in cancer-associated genes and causing single amino acid changes are not associated with increased or reduced risks for breast cancer.
96

Breast Care 2009;4:93-99
Meindl 
Only 2 of 9 amino acid-changing SNPs that were validated in more than 30,000 cases and controls each were statistically significantly associated with a reduced or slightly increased breast cancer risk [22]. One of them is located in the CASP8 gene (rs1045485) and causes a change from aspartic acid to histidine at position $302(\mathrm{D} 302 \mathrm{H})$. The caspase 8 protein plays a role in apoptosis or programmed cell death. As this mechanism is an essential defence against hyperproliferation and cancer, this protein has been selected for investigation. Substitution shows a protective effect with an OR of 0.89 for heterozygous and an OR of 0.74 for the rare homozygous carriers. It has been hypothesized that the D302 change affects autoprocessing of procaspase- 8 molecules. The other SNP is located in the TGFB1 gene (rs1982073) [22] and is responsible for an L10P exchange which provides only a slight increase in breast cancer risk $(\mathrm{OR}=1.07$ for heterozygous and $\mathrm{OR}=1.16$ for homozygous carriers [23]).

It can therefore be expected that the inclusion of many more cases and controls for this approach in the future will overcome the major restriction of insufficient sample sizes. However, the construction and production of even more powerful chips with a significant extension of SNP numbers will gradually replace this approach.

\section{From the Candidate Gene Approach to GWAS: Identification of Rare Intermediate Penetrance Breast Cancer Susceptibility Genes}

The polygenic model for breast cancer requires the interaction of low-risk variants (with variable numbers ranging from 5 to 500) and at least 1 gene mutation conferring a moderate penetrance. A priori, genes harbouring such mutations can be located in different pathways that are associated with tumorigenesis. However, since BRCA1 and BRCA2 are involved in DNA repair and heterozygous mutations in another DNA repair gene like ATM (ataxia telangiactasia mutated) have been associated with increased breast cancer risk [2, 23], candidate gene approaches to identify further breast cancer susceptibility genes in familial cases focussed on other genes involved in DNA repair. These included genes such as CHEK2, BRIP1, and PALB2 (see below). The strong link between DNA repair and breast cancer susceptibility became even more intriguing after homozygous mutations in BRCA2 were found to be responsible for Fanconi anaemia. In fact, homozygous mutations in the BRCA2 gene were shown to cause the complementation group FANCD1 [24]. Notably, mutations in several genes associated with an increased breast cancer risk in monoallelic mutation carriers cause rare subgroups of Fanconi anaemia or other rare autosomal recessive diseases if both alleles are affected. For example, BRIP1 and PALB2, both associated with a moderately increased risk in heterozygous mutation carriers, turned out to be FANCJ and FANCN, respectively. ORs for heterozygous mutations in DNA repair genes like ATM,
CHEK2, BRIP1, PALB2, and RAD50 lie between 2.0 and 4.3 and are thus associated with a moderately increased breast cancer risk (table 1) [25].

ATM mutations are known to cause ataxia teleangiectasia/ Louis-Bar syndrome, an autosomal recessive disorder characterized by cerebellar ataxia, telangiectases, immune defects, and a predisposition to malignancy (MIM 208900). Most recently, screening of 441 BRCA1/BRCA2-negative breast cancer cases from 440 families and 521 controls for ATM sequence variants identified 12 mutations in affected individuals and 2 in controls. By segregation analysis incorporating information from the controls and the full pedigrees of the cases, Renwick et al. [26] estimated a relative breast cancer risk of 2.37 in heterozygous mutation carriers. Therefore, ATM can currently be classified as a breast cancer susceptibility gene with intermediate penetrance.

CHEK2 is activated by ATM in response to DNA doublestrand breaks and subsequently phosphorylates BRCA1. In some cases, mutations in CHEK2 cause Li-Fraumeni syndrome (LFS2) (MIM 609265). The CHEK2 1100delC frameshift mutation in exon 10 , causing a truncated protein, displayed a 2-fold increased breast cancer risk in female heterozygous mutation carriers [27]. Most recently, the results of a metaanalysis (combined analysis of different population studies) for the assessment of breast cancer risk in CHEK2 1100delC carriers of more than 50,000 cases and controls reported on a 4.8 relative risk of developing breast cancer for heterozygous CHEK2 1100delC mutation carriers with a family history of breast cancer. This leads to an estimated cumulative breast cancer risk of $37 \%$ by the age of 70 [28]. However, carrier frequencies are ranging from 0.7 to $0.2 \%$ (table 2). Moreover, screening of all 14 coding exons in 516 BRCA1/BRCA2 mutation-negative hereditary breast cancer families displayed incomplete segregation of CHEK2 1100delC in families with breast cancer [29]. However, CHEK2 1100delC carriers seem to have both poorer disease-free and overall survival than non-carriers. Furthermore, an increased risk of developing a second, mostly contralateral breast cancer has been observed in CHEK2 1100delC mutation carriers having received initial radiotherapy [30].

Mutations in BRIP1, previously known as BACH1, were demonstrated to be associated with increased breast cancer risk. Screening for constitutional BRIP1 mutations in 1,212 individuals with breast cancer from BRCA1/BRCA2 mutationnegative families and 2,081 controls identified 9 and 2 truncating mutations in individuals with breast cancer and controls, respectively. This leads to an estimated relative risk of breast cancer of 2.0 in heterozygous mutation carriers, while biallelic mutations cause Fanconi anaemia, complementation group $\mathbf{J}$ (MIM 609054) [31].

Screening of the PALB2 gene, known to cause Fanconi anaemia complementation group N (MIM 610832), in 923 distinct families and 1,084 healthy controls led to the identification of 10 truncating PALB2 mutations in individuals 
Table 2. Frequencies of moderate and low-risk variants

\begin{tabular}{|c|c|c|c|}
\hline Gene/locus & $\begin{array}{l}\text { Mutation/ } \\
\text { reference SNP }\end{array}$ & Population & $\begin{array}{l}\text { Allele } \\
\text { frequency, \% }\end{array}$ \\
\hline \multicolumn{4}{|c|}{ Rare moderate penetrance breast cancer susceptibility genes } \\
\hline ATM & mutations & Western population & $0.25-0.5$ \\
\hline BRIP1 & mutations & UK & 0.15 \\
\hline \multirow[t]{12}{*}{ CHEK2 } & 1100delC & Netherlands & $0.7-1.3$ \\
\hline & & Finland & $0.55-0.7$ \\
\hline & & UK & $0.18-0.25$ \\
\hline & & Germany & $0,075-0,125$ \\
\hline & & Australia & 0.07 \\
\hline & & Sweden & $0.3-0.5$ \\
\hline & & Poland & $0.1-0,125$ \\
\hline & & Czech Republic & 0.15 \\
\hline & & Italy & 0,055 \\
\hline & & USA & $0.15-0.2$ \\
\hline & & Canada & 0.1 \\
\hline & & Spain & no detection \\
\hline PALB2 & mutations & UK & 0.25 \\
\hline \multicolumn{4}{|c|}{ Common low penetrance breast cancer susceptibility SNPs } \\
\hline \multirow[t]{3}{*}{ FGFR2 } & rs1219648 & USA/ European ancestry & 39 \\
\hline & rs2981582 & UK & 38 \\
\hline & & Asia & 30 \\
\hline \multirow[t]{2}{*}{ LSP1 } & rs3817198 & UK & 30 \\
\hline & & Asia & 14 \\
\hline \multirow[t]{2}{*}{ MAP3K1 } & rs889312 & UK & 28 \\
\hline & & Asia & 54 \\
\hline TGFB1 & L10P & Western population & 38 \\
\hline \multirow{3}{*}{ TOX3 } & rs 3803662 & Western population & 14 \\
\hline & rs3803662 & UK & 25 \\
\hline & & Asia & 60 \\
\hline $2 \mathrm{q} 35$ & rs13387042 & Western population & 25 \\
\hline \multirow[t]{2}{*}{$8 \mathrm{q}$} & rs13281615 & UK & 40 \\
\hline & & Asia & 56 \\
\hline
\end{tabular}

$\mathrm{SNP}=$ Single nucleotide polymorphism .

with hereditary breast cancer, while there were no truncating mutations in controls [32]. Similar to former reports on breast cancer families carrying mutations in ATM, CHEK2, or BRIP1, incomplete segregation of the PALB2 mutations were observed. Overall, ATM, BRIP1, CHEK2, and PALB2 mutations, harbouring each rare mutations with intermediate penetrance, collectively account for only approximately $2.3 \%$ of the overall familial risk $[2,26]$. It remains open whether in the near future additional genes conferring moderate penetrance can be identified by deciphering pathways other than DNA repair that are associated with tumorigenesis. However, there is no reason why this should not be accomplished.

A novel and very encouraging finding for the counselling and management of sporadic cases is that such variants also occur here. Indeed, mutations in at least some of these genes are not restricted to BRCA1/BRCA2-negative familial cases but can also occur in sporadic cases. Likewise, CHEK2 deletions [33] and a PALB2 Finnish founder mutation have also been identified in single cases [34]. Thus, it is likely that the identification of additional gene mutations conferring moderate penetrance will improve the counselling of first degree relatives of single cases of breast cancer. Two recent observations substantiate this assumption: firstly, a Chinese group reported an association of PALB2 polymorphisms with an elevated breast cancer risk [35], and we were able to show for the German population that PALB2 mutations occur with similar frequency in hereditary and sporadic cases [Hellebrand et al., personal communication].

\section{Diagnostic and Clinical Consequences of Mutations Conferring Moderate Penetrance}

Due to the rareness and incomplete segregation of mutations conferring moderate penetrance, complete sequencing of genes like ATM, BRIP1, CHEK2, PALB2 in BRCA1/ BRCA2-negative high-risk breast cancer families and sporadic cases diagnosed before the age of 50 is currently not justified. However, in the near future, as soon as costs and time of sequencing are reduced to a more reasonable level, it may become cost-effective to screen all genes involved in DNA repair or other breast cancer-associated pathways in high-risk families and premenopausal cases of breast cancer. Furthermore, due to the known differences in allele frequency, e.g. the rather high frequency of CHEK2 1100delC in the Netherlands or Finland, genetic testing of certain mutations and/or polymorphisms associated with a significantly increased breast cancer risk can in the beginning be restricted to populations with relatively high allele frequencies. Finally, it remains to be disclosed to what extend one of the 2 prominent low-risk variants (FGFR2 or TOX3) occurs together with one of the moderate-penetrance mutations.

\section{Future Perspectives for GWAS and the Detection of Mutations with Moderate Penetrance}

In the meantime, several thousand familial cases exhibiting no mutation in the 2 known BRCA genes have been collected and characterized. The combined analysis of such cases by GWAS is now able to detect novel susceptibility genes for breast cancer independent of a candidate gene approach. The German Consortium plans to analyse about 2,000 such cases, and the English Centers are preparing the investigation of about 4,000 familial cases by this technique. This number of analysed cases should be sufficient to detect with statistical significance moderate variants which are, for example, present with a $0.5-1 \%$ frequency in the controls and a $3-5 \%$ frequency in the cases. Moreover, the detection of additional gene variants or mutations causing an intermediate risk for breast cancer will hopefully pave the way to novel pathways associated with breast cancer initiation or progression. 


\section{Conclusions}

GWAS has been a powerful strategy to detect novel susceptibility genes conferring low risks for breast cancer. Although it requires rather large samples of both cases and controls, it can reliably determine common variants as low-risk alleles. Moreover, by including larger numbers in future stage I GWAS experiments (approximately 1,500 cases and controls each), the identification of significant numbers of 'false positives' might be avoided. Indeed, the judicious clinical translation of genetic factors beyond BRCA1/BRCA2 requires the identification and replication of many more such variants. In addition, these efforts have to be implemented by the identification of additional gene mutations conferring intermediate risks by the combined application of GWAS and genome-wide sequencing for pronounced familial cases. The latter approach might also reveal additional rare but highly penetrant gene mutations. While for the majority of breast cancer cases (about 80\%) - the sporadic ones - the clinical impact of single low-risk variants is limited, the combination of a few susceptibility genes, which in the near future will include genes conferring moderate penetrance, may successfully separate women who are at high risk from those who are at low risk for breast cancer.

\section{Conflict of Interest}

The author declares that he has no conflict of interest.

\section{References}

1 Easton DF, Pooley KA, Dunning AM, et al: Genomewide association study identifies novel breast cancer susceptibility loci. Nature 2007;447:1087-1093

- Turnbull C, Rahman N: Genetic predisposition to breast cancer: past, present, and future. Annu Rev Genomics Hum Genet 2008;9:321-345

$\checkmark 3$ Hunter DJ, Kraft P, Jacobs KB, et al: A genomewide association study identifies alleles in FGFR2 associated with risk of sporadic postmenopausal breast cancer. Nat Genet 2007;39:870-874.

4 Willems PJ: Susceptibility genes in breast cancer: more is less? Clin Genet 2007;72:493-496.

5 Seng KC, Seng CK: The success of the genomewide association approach: a brief story of a long struggle. Eur J Hum Genet 2008;16:554-564.

6 Stacey SN, Manolescu A, Sulem P, et al: Common variants on chromosomes $2 \mathrm{q} 35$ and $16 \mathrm{q} 12$ confer susceptibility to estrogen receptor-positive breast cancer. Nat Genet 2007;39:865-869.

7 Gold B, Kirchhoff T, Stefanov S, et al: Genomewide association study provides evidence for a breast cancer risk locus at 6q22.33. Proc Natl Acad Sci U.S.A 2008;105:4340-4345.

$\checkmark 8$ Meyer KB, Maia AT, O'Reilly M, et al: Allele-specific up-regulation of FGFR2 increases susceptibility to breast cancer. PLoS Biol 2008;6:e108.

$\checkmark$ Antoniou AC, Spurdle AB, Sinilnikova OM, et al: Common breast cancer-predisposition alleles are associated with breast cancer risk in BRCA1 and BRCA2 mutation carriers. Am J Hum Genet 2008;82:937-948.

10 Schmutzler R, Schlegelberger B, Meindl A, Gerber WD, Kiechle M: (Counselling, genetic testing and prevention in women with hereditary breast- and ovarian cancer. Interdisciplinary recommendations of the consortium 'Hereditary Breast and Ovarian Cancer' of the German Cancer AiD). Zentralbl Gynakol 2003;125:494-506.

11 McIntosh A, Shaw C, Evans G, Turnbull N, Bahar N, Barclay M, Easton D, Emery J, Gray J, Halpin J, Hopwood P, McKay J, Sheppard C, Sibbering M, Watson W, Wailoo A, Hutchinson A: Clinical guidelines and evidence review for the classification and care of women at risk of familial breast cancer (NICE guidelines CG014). London, National Collaborating Centre for Primary Care, University of Sheffield, 2004
12 Marroni F, Aretini P, D'Andrea E, et al: Evaluation of widely used models for predicting BRCA1 and BRCA2 mutations. J Med Genet 2004;41:278-285.

13 Antoniou AC, Cunningham AP, Peto J, et al: The BOADICEA model of genetic susceptibility to breast and ovarian cancers: updates and extensions. Br J Cancer 2008;98:1457-1466.

14 Offit K, Garber JE: Time to check CHEK2 in families with breast cancer? J Clin Oncol 2008;26:519520.

15 Silva E, Gatalica Z, Snyder C, Vranic S, Lynch JF, Lynch HT: Hereditary breast cancer: part II. Management of hereditary breast cancer: implications of molecular genetics and pathology. Breast $\mathrm{J}$ 2008;14:14-24.

16 Pharoah PD, Antoniou AC, Easton DF, Ponder BA: Polygenes, risk prediction, and targeted prevention of breast cancer. N Engl J Med 2008;358:2796-2803.

17 Cassiman JJ: Research network: EuroGentest - a European Network of Excellence aimed at harmonizing genetic testing services. Eur J Hum Genet 2005;13:1103-1105.

18 Scheuner MT, Sieverding P, Shekelle PG: Delivery of genomic medicine for common chronic adult diseases: a systematic review. JAMA 2008;299:13201334.

20 Fagerholm R, Hofstetter B, Tommiska J, et al: NAD(P)H:quinone oxidoreductase 1 NQO1*2 genotype (P187S) is a strong prognostic and predictive factor in breast cancer. Nat Genet 2008;40:844-853.

21 Garcia-Closas M, Hall P, Nevanlinna H, et al: Heterogeneity of breast cancer associations with five susceptibility loci by clinical and pathological characteristics. PLoS Genet 2008;4:e1000054.

22 Thubass C, Naehrig J, Streit S, et al: FGFR4 Arg388 allele is associated with resistance to adjuvant therapy in primary breast cancer. J Clin Oncol 2006;24:3747-3755.

23 Cox A, Dunning AM, Garcia-Clossas M, et al: A common coding variant in CASP8 is associated with breast cancer risk. Nat Genet 2007;39:352-358.

24 Ripperger T, Gadzicki D, Meindl A, Schlegelberger B: Breast cancer susceptibility: current knowledge and implications for genetic counselling. Eur J Hum Genet 2008; Epub ahead of print, doi:1038/ ejhg.2008,212
25 Wang W: Emergence of a DNA-damage response network consisting of Fanconi anaemia and BRCA proteins. Nat Rev Genet 2007;8:735-748.

26 Walsh T, King MC: Ten genes for inherited breast cancer. Cancer Cell 2007;11:103-105.

27 Renwick A, Thompson D, Seal S, et al: ATM mutations that cause ataxia-telangiectasia are breast cancer susceptibility alleles. Nat Genet 2006;38: 873-875.

28 Nevanlinna H, Bartek J: The CHEK2 gene and inherited breast cancer susceptibility. Oncogene 2006;25:5912-5919.

29 Weischer M, Bojesen SE, Ellervik C, TybjaergHansen A, Nordestgaard BG: CHEK2*1100delC genotyping for clinical assessment of breast cancer risk: meta-analyses of 26,000 patient cases and 27,000 controls. J Clin Oncol 2008;26:542-548.

30 Dufault MR, Betz B, Wappenschmidt B, et al: Limited relevance of the CHEK2 gene in hereditary breast cancer. Int J Cancer 2004;110:320-325.

31 Schmidt MK, Tollenaar RA, de Kemp SR, et al: Breast cancer survival and tumor characteristics in premenopausal women carrying the CHEK2*1100delC germline mutation. J Clin Oncol 2007;25:64-69.

32 Seal S, Thompson D, Renwick A, et al: Truncating mutations in the Fanconi anemia J gene BRIP1 are low-penetrance breast cancer susceptibility alleles. Nat Genet 2006;38:1239-1241.

33 Rahman N, Seal S, Thompson D, et al: PALB2, which encodes a BRCA2-interacting protein, is a breast cancer susceptibility gene. Nat Genet 2007;39: 165-167.

34 Bogdanova N, Feshchenko S, Cybulski C, Doerk T: CHEK2 mutation and hereditary breast cancer. J Clin Oncol 2007:25:26e.

35 Erkko H, Xiam B, Nikkilä J, et al: A recurrent mutation in PALB2 in Finnish cancer families. Nature 2007:446:316-319. 